RESEARCH REPORT

\title{
Neighbourhood unemployment and all cause mortality: a comparison of six countries
}

\author{
F J van Lenthe, L N Borrell, G Costa, A V Diez Roux, T M Kauppinen, C Marinacci, P Martikainen, \\ E Regidor, M Stafford, T Valkonen
}

See end of article for authors' affiliations

Correspondence to: Dr F J van Lenthe Department of Public Health, Erasmus Medical Centre, Rotterdam, PO Box 1738,3000 DR

Rotterdam, Netherlands; f.vanlenthe@erasmusmc.nl

Accepted for publication 6 July 2004
Study objective: Studies have shown that living in more deprived neighbourhoods is related to higher mortality rates, independent of individual socioeconomic characteristics. One approach that contributes to understanding the processes underlying this association is to examine whether the relation is modified by the country context. In this study, the size of the association between neighbourhood unemployment rates and all cause mortality was compared across samples from six countries (United States, Netherlands, England, Finland, Italy, and Spain).

Design: Data from three prospective cohort studies (ARIC (US), GLOBE (Netherlands), and Whitehall II (England)) and three population based register studies (Helsinki, Turin, Madrid) were analysed. In each study, neighbourhood unemployment rates were derived from census, register based data. Cox proportional hazard models, taking into account the possible correlation of outcomes among people of the same neighbourhood, were used to assess the associations between neighbourhood unemployment and all cause mortality, adjusted for education and occupation at the individual level.

Results: In men, after adjustment for age, education, and occupation, living in the quartile of neighbourhoods with the highest compared with the lowest unemployment rates was associated with increased hazards of mortality (14\%-46\%), although for the Whitehall II study associations were not statistically significant. Similar patterns were found in women, but associations were not statistically significant in two of the five studies that included women.

Conclusions: Living in more deprived neighbourhoods is associated with increased all cause mortality in the US and five European countries, independent of individual socioeconomic characteristics. There is no evidence that country substantially modified this association.
1 $\mathrm{n}$ the past years, the adverse health consequences of living in deprived neighbourhoods have been increasingly recognised. Several, although not all studies reported an increased risk of death of residents living in poverty areas, after adjustment for individual socioeconomic factors. ${ }^{1-7}$ The underlying mechanisms for this association however, remain to be further explored. One approach to understanding more about the processes linking the neighbourhood socioeconomic environment to mortality is to compare data across several countries. The presence of differences in these associations across countries would prompt further investigation of what specific country level factors increase or attenuate neighbourhood effects.

Methodological differences in studies published thus far, for example in the measurement of the neighbourhood socioeconomic environment, the adjustment for different (numbers of) socioeconomic indicators at the individual level, and differences in the statistical analysis, hamper a valid cross country comparison. This study extends the literature on the association between the residential environment and health by comparing the effects of the neighbourhood unemployment on all cause mortality in six countries, based on a cooperatively developed plan of analysis.

\section{METHODS}

\section{Description of studies}

Data on mortality, neighbourhood unemployment, and individual socioeconomic indicators were obtained from three prospective cohort studies in which samples were followed up over time (the ARIC study, US ${ }^{8}$; the GLOBE study, Netherlands; ; the Whitehall II study, England $\left.{ }^{8-10}\right)$, and three population based registry studies based on coverage of almost entire general populations (Helsinki metropolitan area, Finland, ${ }^{4}$ Turin, Italy, ${ }^{11}$ and Madrid, Spain ${ }^{12}$ ). Table 1 provides an overview of the data sources. Baseline data in all studies were collected from 1985 onwards. Study populations included men and women aged $15-75$ years of age. The ARIC study is carried out in four regions: Forsyth County NC, Jackson MS, north western suburbs of Minneapolis MN, and Washington County MD. In three of the four regions, the population reflects the demographic composition of the communities from which they were chosen (with predominantly, but not exclusively, white subjects). In the fourth region (Jackson) only black people were sampled. To make the six study populations in our study more comparable (and because the investigation of ethnic differences raises additional issues) analyses in the ARIC study were restricted to the three regions including mainly white people. Neighbourhoods were defined using existing administrative or geographical boundaries with the median number of residents per neighbourhood varying from $n=1220$ in the study in Madrid to $\mathrm{n}=14090$ in the study in Helsinki (table 2).

\section{Neighbourhood level data}

Neighbourhood unemployment was used as an indicator of the neighbourhood socioeconomic environment. Unemployment was selected as the neighbourhood indicator because it was the variable that was available systematically across studies. Information on unemployment rates was derived from census based data in all studies. In all countries except Spain and the US, neighbourhood unemployment was 
Table 1 Overview of data sources

\begin{tabular}{|c|c|c|c|c|c|c|}
\hline Country & City & Study & $\begin{array}{l}\text { Estimated number } \\
\text { residents }\end{array}$ & Study design & Sample size & Sample description \\
\hline USA & Three US regions* & ARIC & 244580 & Prospective cohort & 10210 & $\begin{array}{l}\text { Random sample of residents of three US } \\
\text { communities }\end{array}$ \\
\hline Netherlands & Eindhoven & GLOBE & 190000 & Prospective cohort & 9530 & Random sample of residents of Eindhoven \\
\hline England & London & Whitehall II & 7000000 & Prospective cohort & 9740 & $\begin{array}{l}\text { Occupation based cohort of British civil } \\
\text { workers }\end{array}$ \\
\hline Finland & Helsinki† & Helsinki & 800000 & Population based & 270050 & Male population of Helsinki \\
\hline Italy & Turin & Turin & 920000 & Population based & 565844 & Population of Turin \\
\hline Spain & Madrid & Madrid & 2889000 & Population based & 1936726 & Population of Madrid \\
\hline Country & City & Study & Baseline & $\begin{array}{l}\text { Age range (years) at } \\
\text { baseline }\end{array}$ & $\begin{array}{l}\text { Median follow up } \\
\text { years (range) }\end{array}$ & Number of deaths \\
\hline USA & Four US regions* & ARIC & 1987-1989 & $45-65$ & $10.9(0.1-14.3)$ & 915 \\
\hline Netherlands & Eindhoven & GLOBE & 1991 & $15-74$ & $7.2(0.1-7.5)$ & 630 \\
\hline England & London & Whitehall II & $1985-1988$ & $35-55$ & $14.6(6.0-16.3)$ & 431 \\
\hline Finland & Helsinki† & Helsinki & 1990 & $20-74$ & $5.0(0.0-5.0)$ & 10401 \\
\hline Italy & Turin & Turin & 1991 & $20-75$ & $9.20(0.0-9.2)$ & 26620 \\
\hline Spain & Madrid & Madrid & 1996 & $20-75$ & $1.7(0.0-1.7)$ & 15142 \\
\hline
\end{tabular}

calculated by dividing the number of unemployed persons (for example, actively seeking employment, thus excluding housewives, retirees, and students) by the total number of persons in the working age population (in general between 15 and 65 years of age). In Spain and the US, neighbourhood unemployment was defined as the population of unemployed persons among the economically active population in the working age population. Thus, instead of the entire working age population, the denominator in the Spanish and US definitions excluded persons not economically active or not in the labour force (for example, housewives, students, retirees). The substantial higher neighbourhood unemployment rates in Spain may be partly caused by this methodological deviation from the other studies, but they are also "real", as Spain is among the European countries with the highest unemployment rates.

\section{Individual level data}

Although different approaches were used to collect information on mortality, all studies had nearly complete mortality data, with the exception of the study in Madrid. In the ARIC study, information on all cause mortality was obtained through annual follow up phone calls, hospital surveillance, and vital statistics databases as well as National Death Index searches. ${ }^{13}$ In the GLOBE study, information on mortality was collected annually via municipal population registers. ${ }^{14}$ These registers cover the population completely and are maintained continuously with respect to death and changes of address. In the Whitehall II study, mortality was obtained via information from death certificates from vital statistical offices. In Helsinki, the 1990 census records of all men aged 20 years and older living in the Helsinki metropolitan area were linked to death records from 1991 until 1995. Records were linked by Statistics Finland using the personal identification codes. Less than $1 \%$ of the deaths could not be linked to census records. In Turin, information on mortality was directly obtained from the municipality population registry; the follow up covered the entire study population, which was selected among census residents linked to the population registry (linkage was successful for $96.6 \%$ of the total population in the census). In Spain, the 1996 population census and the 1996 and 1997 mortality registries were linked, using personal characteristics. Linkage was successful for $70 \%$ of all deceased persons. However, no significant differences were observed in sex, age, or residential area between deceased persons linked and those not linked.

Individual socioeconomic indicators included were education and occupation at baseline. Efforts were made to use indicators and categories as similar as possible across countries. Appendix 1 describes the categories used in all studies (available on line http://www.jech.com/supplemental). In each study, groups of education were distinguished based on the highest levels of education obtained. Whenever possible categories were constructed so they were comparable to the International Standard Classification of Education ${ }^{15}$ (ranging from low to high education: $1=$ ISCED levels 0 and 1; $2=$ ISCED level 2;3= ISCED levels 3 and $4 ; 4=$ ISCED levels 5 and 6).

In all studies, information about baseline current occupation was available. There were differences between studies in the treatment of those without a current occupation, such as homemakers, retirees, and unemployed. In the ARIC study, homemakers were in a separate category, in the GLOBE study all persons were asked for their current or last occupation with those without a job ever (for example, students, housewives, etc) classified in a separate group. In the occupation based cohort of Whitehall II there were no persons without a current occupation. In Helsinki those without a current job were classified according to their last

Table 2 Neighbourhood characteristics

\begin{tabular}{lllll}
\hline Study & $\begin{array}{l}\text { Definition of } \\
\text { neighbourhood }\end{array}$ & $\begin{array}{l}\text { Number of } \\
\text { neighbourhoods } \\
\text { included in study }\end{array}$ & $\begin{array}{l}\text { Median number of residents } \\
\text { (range) }\end{array}$ & $\begin{array}{l}\text { Median number of study participants per } \\
\text { neighbourhood (range) }\end{array}$ \\
\hline ARIC & Block groups & 443 & $1633(347-4773)$ & $19(1-136)$ \\
GLOBE & Administrative & 84 & $2025(86-9807)$ & $113(4-352)$ \\
Whitehall II & Electoral wards & 2207 & $6,237(717-29071)$ & $2(1-55)$ \\
Helsinki & Administrative & 55 & $14,090(3699-26401)$ & $4733(1229-9155)$ \\
Turin & Administrative & 92 & $7986(40-29789)$ & $4,872(24-19012)$ \\
Madrid & Census tracts & 2136 & $1220(451-3894)$ & $894(318-3116)$ \\
\hline
\end{tabular}


Table 3 Descriptive information by quartiles of neighbourhood unemployment

\begin{tabular}{|c|c|c|c|c|}
\hline & \multicolumn{4}{|c|}{ Neighbourhood unemployment (quartiles) } \\
\hline & $\begin{array}{l}1 \text { (least } \\
\text { unemployment) }\end{array}$ & 2 & 3 & $\begin{array}{l}4 \text { (most } \\
\text { unemployment) }\end{array}$ \\
\hline \multicolumn{5}{|c|}{ Cut points $(\%)^{*}$} \\
\hline ARIC & $<1.9$ & 1.9 to 3.5 & 3.5 to 5.4 & $>5.4$ \\
\hline GLOBE & $<4.8$ & 4.8 to 7.7 & 7.8 to 9.7 & $>9.7$ \\
\hline Whitehall II & $<3.9$ & 3.9 to 5.1 & 5.2 to 7.6 & $>7.6$ \\
\hline Helsinki & $<1.02$ & 1.02 to 1.30 & 1.31 to 1.63 & $>1.63$ \\
\hline Turin & $<6.2$ & 6.2 to 8.2 & 8.3 to 10.2 & $>10.2$ \\
\hline Madrid & $<18.8$ & 18.8 to 21.8 & 21.9 to 25.3 & $>25.3$ \\
\hline \multicolumn{5}{|c|}{ Mean age in years (SD) } \\
\hline ARIC & $54.4(5.8)$ & $54.2(5.6)$ & $54.6(5.7)$ & $55.2(5.6)$ \\
\hline GLOBE & $47.9(13.9)$ & $50.1(14.7)$ & $48.3(16.1)$ & $48.6(16.2)$ \\
\hline Whitehall II & $44.6(6.0)$ & $44.6(6.0)$ & $44.2(6.0)$ & $44.5(6.2)$ \\
\hline Helsinki & $42.1(13.6)$ & $41.8(14.0)$ & $41.6(14.0)$ & 41.5 (13.7) \\
\hline Turin & 46.5 (13.5) & $45.0(13.6)$ & 44.5 (13.7) & 43.9 (13.9) \\
\hline Madrid & 45.5 & 45.1 & 45 & 43.7 \\
\hline \multicolumn{5}{|l|}{ Men $(\%)$} \\
\hline ARIC regions & 46.9 & 47.0 & 47.5 & 48.7 \\
\hline GLOBE & 49.6 & 46.7 & 49.0 & 49.4 \\
\hline Whitehall II & 81.0 & 72.9 & 67.7 & 51.3 \\
\hline Helsinki & 100 & 100 & 100 & 100 \\
\hline Turin & 46.5 & 47.8 & 48.4 & 49.4 \\
\hline Madrid & 46.2 & 46.2 & 47.1 & 47.5 \\
\hline \multicolumn{5}{|c|}{ Low education $(\%) \dagger$} \\
\hline ARIC & 13.3 & 16.9 & 19.8 & 22.8 \\
\hline GLOBE & 11.2 & 24.6 & 22.6 & 30.1 \\
\hline Whitehall II & 4.7 & 7.0 & 7.1 & 11.5 \\
\hline Helsinki & 28.4 & 33.5 & 36.3 & 41.0 \\
\hline Turin & 19.8 & 28.5 & 33.2 & 40.2 \\
\hline Madrid & 19.1 & 30.0 & 40.3 & 51.6 \\
\hline \multicolumn{5}{|c|}{ Higher grade professionalsł } \\
\hline ARIC & 32.6 & 29.1 & 24.0 & 20.6 \\
\hline GLOBE & 14.2 & 6.3 & 6.4 & 5.5 \\
\hline Whitehall II & 42.4 & 36.7 & 27.0 & 16.0 \\
\hline Helsinki & 37.3 & 29.2 & 25.0 & 19.8 \\
\hline Turin & 4.9 & 2.0 & 1.6 & 0.8 \\
\hline Madrid & 39.8 & 26.7 & 16.3 & 8.9 \\
\hline \multicolumn{5}{|c|}{$\begin{array}{l}\text { *Quartiles are derived from census based data. †Definitions of lowest education: ARIC: less than high school, } \\
\text { GLOBE: primary school Whitehall II: no academic qualifications, Helsinki: up to nine years of education, Turin: } \\
\text { primary, Madrid: primary education and lower. IHighest categories are presented because they are more } \\
\text { comparable between countries than the lowest occupational categories. Definitions are: ARIC: executive, } \\
\text { managerial and professional, GLOBE: higher grade professionals, Whitehall II: higher (executives, top managers), } \\
\text { Helsinki: upper white collar, Turin: higher grade white collar, Madrid: higher grade professionals. }\end{array}$} \\
\hline
\end{tabular}

job. In Turin last occupation was used for unemployed and retired persons, the latter based on the 1981 census, and housewives were in the same group as blue collar workers. In Madrid those without a current job were in a group called "other".

\section{Statistical analysis}

Participants with missing values for any of the variables listed above were excluded from the analysis. Cut off points were calculated for country specific quartiles of neighbourhood unemployment and descriptive analyses were carried out by these quartiles. Analyses were carried out for men and women separately. Age adjusted mortality rates by neighbourhood unemployment quartiles were calculated, using Poisson regression analysis. Cox proportional hazard models were used to assess the hazard ratio (HR) of living in the three quartiles with increased levels of neighbourhood unemployment, compared with the reference quartile (lowest unemployment rates). In model 1 , this association was adjusted for individual age of study participants and in model 2 we additionally adjusted for personal education and occupation. In the proportional hazard models, the within neighbourhood correlation was taken into account by estimating the robust sandwich estimators in the PHREG procedure in SAS (version 8.2). Currently, multilevel models are mostly used in simultaneous analyses of neighbourhood and individual level data. We refrained from using this technique however, given the development stage of multilevel Cox proportional hazard models, and our primary interest in the comparison of the fixed effects between studies. In Helsinki and Madrid, the hazard ratios were analysed using multilevel random intercepts Poisson analysis with the GLIMMIX macro in SAS. This was done because the individual level data were available in a cross tabulated form according to the variables included in the analysis. Each cell in the table included information on the number of deaths and the number of person years lived during the follow up period, and the cell was taken to be the unit of analysis. Analyses were carried out separately by researchers in each of the studies.

\section{RESULTS}

Country specific cut off points of quartiles of neighbourhood unemployment were approximately similar in the ARIC, GLOBE, and Whitehall II studies and in Turin (table 3). Cut off points of quartiles of neighbourhood unemployment were substantially lower in Helsinki and substantially higher in Madrid. The mean age of the participants was about 45 years in all studies, with participants in the ARIC and GLOBE study being slightly older on average. All studies included about equal numbers of men and women, except in Whitehall II (most being men) and Helsinki (only men included). Although absolute percentages varied between countries, patterns of increasing percentages of lower educated 


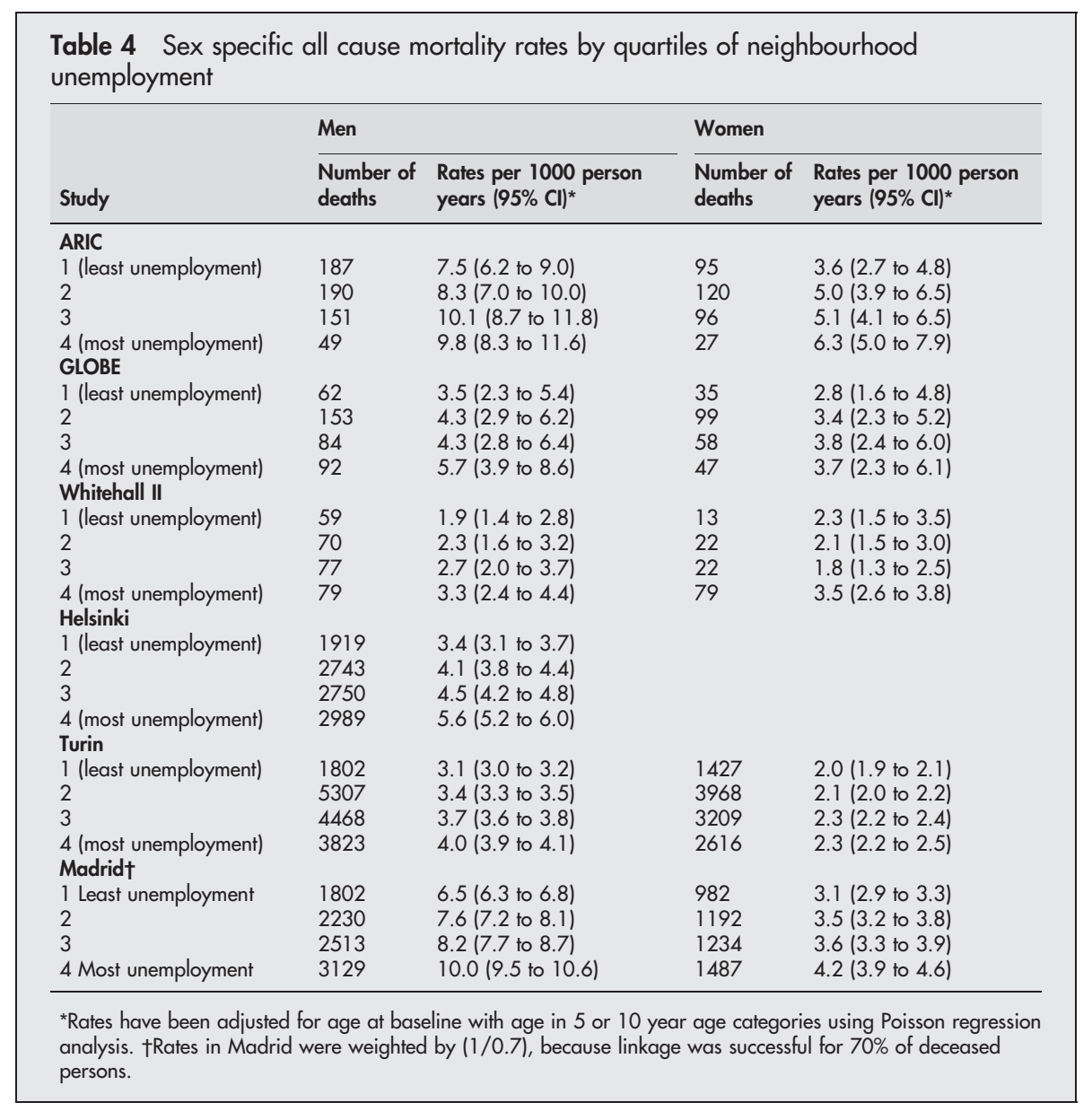

participants and decreasing percentages of higher grade professionals by increasing neighbourhood unemployment quartiles were found in all studies.

In all studies, and both in men and women (except in women in London), mortality rates increased with increasing quartiles of neighbourhood unemployment (table 4). Adjusted for age, increasing hazard ratios were found by increasing quartiles of neighbourhood unemployment in all studies in men (table 5). The age adjusted hazard ratio in the highest compared with the lowest quartile of neighbourhood unemployment was highest in the Whitehall II study $(\mathrm{HR}=1.70,95 \%$ CI 1.22 to 2.36$)$ and lowest in Turin $(\mathrm{HR}=1.28,95 \%$ CI 1.23 to 1.35$)$. Additional adjustment for individual levels of education and occupation attenuated the hazard ratios from 31\% (GLOBE) to $73 \%$ (Whitehall II). Hazard ratios of living in the quartile with the highest compared with the lowest unemployment rates remained significantly increased in all studies, except in the Whitehall II study ( $\mathrm{HR}=1.19,95 \%$ CI 0.79 to 1.78 ). In the ARIC study a significant association was found in the third but not in the fourth quartile.

In women, essentially similar patterns were observed, but confidence intervals were wider because of the lower number of deaths. Age adjusted hazard ratios attenuated after adjustment for education and occupation and were significantly increased in the ARIC study ( $\mathrm{HR}=1.63,95 \%$ CI 1.20 to $2.22)$, in Turin ( $\mathrm{HR}=1.12,95 \% \mathrm{CI} 1.05$ to 1.20$)$, and in Madrid $(\mathrm{HR}=1.24,95 \%$ CI 1.13 to 1.36$)$.

\section{DISCUSSION}

In this study, a pattern of increasing hazard ratios of mortality with increasing neighbourhood unemployment rates was found in samples in six countries. Additional adjustment for education and occupation of study participants attenuated the hazard ratios to modest values, but hazard ratios of living in the quartiles of the highest compared with the lowest unemployment rates remained significantly increased in men (except for the Whitehall II study) and, less consistently, in women (for the ARIC study, Madrid, and Turin).

A strength of this study is the inclusion of data from the US, and five European countries geographically varying from the north (Finland) to the middle (United Kingdom and the Netherlands) and to the south of Europe (Italy and Spain). Furthermore, we used similar socioeconomic indicators at both the neighbourhood and individual level in all countries, and analysed data according to a cooperatively developed plan of analysis. Nevertheless, methodological differences between the studies may have influenced the comparability of the results. Firstly, although studies were carried out in urban settings (with the exception of Forsyth County in the ARIC study), the sizes of the cities included varied considerably. It is possible that deprivation related characteristics affect health differently in cities of different sizes. A Dutch study however, suggests that associations between neighbourhood deprivation and self reported health in 25-64 year old adults are rather similar in cities of different sizes. ${ }^{16}$ We also did not find substantial differences across the six studies despite differences in the areas included in each study. Secondly, two different designs were used to assess the associations in the studies. Clearly an important difference between the population based register studies and the prospective cohort studies was the number of deaths included and therefore the statistical power to detect 
Table 5 Sex specific hazard ratios for all cause mortality according to neighbourhood unemployment before and after adjustment for individual socioeconomic indicators

\begin{tabular}{|c|c|c|c|c|}
\hline & \multicolumn{2}{|l|}{ Men } & \multicolumn{2}{|l|}{ Women } \\
\hline & \multicolumn{2}{|l|}{ Hazard ratio $(95 \% \mathrm{Cl})$} & \multicolumn{2}{|l|}{ Hazard ratio $(95 \% \mathrm{Cl})$} \\
\hline & Model $1^{*}$ & Model 2 & Model 1* & Model 2 \\
\hline \multicolumn{5}{|l|}{ ARIC } \\
\hline 1 (least unemployment) & 1.00 & 1.00 & 1.00 & 1.00 \\
\hline 2 & $1.11(0.88$ to 1.41$)$ & 1.08 (0.85 to 1.38 ) & 1.41 (0.99 to 2.01$)$ & 1.40 (1.00 to 1.97$)$ \\
\hline 3 & $1.36(1.08$ to 1.71$)$ & 1.29 (1.03 to 1.61$)$ & 1.44 (1.05 to 1.97$)$ & 1.38 (1.01 to 1.88$)$ \\
\hline 4 (most unemployment) & $1.32(1.04$ to 1.68$)$ & 1.21 (0.96 to 1.53 ) & 1.75 (1.28 to 2.40$)$ & 1.63 (1.20 to 2.22$)$ \\
\hline Percentage reduction in hazard ratio $\dagger$ & & 34 & & 16 \\
\hline \multicolumn{5}{|l|}{ GLOBE } \\
\hline 1 (least unemployment) & 1.00 & 1.00 & 1.00 & 1.00 \\
\hline 2 & $1.22(0.97$ to 1.55$)$ & $1.12(0.89$ to 1.41$)$ & 1.23 (0.86 to 1.77$)$ & $1.13(0.80$ to 1.61$)$ \\
\hline 3 & $1.22(0.91$ to 1.54$)$ & 1.11 (0.84 to 1.47$)$ & 1.36 (0.91 to 2.02$)$ & $1.26(0.85$ to 1.87$)$ \\
\hline 4 (most unemployment) & $1.67(1.25$ to 2.22$)$ & 1.46 (1.09 to 1.95$)$ & $1.33(0.83$ to 2.13$)$ & 1.19 (0.77 to 1.85 ) \\
\hline $\begin{array}{l}\text { Percentage reduction in hazard ratio } \\
\text { Whitehall II }\end{array}$ & \multicolumn{3}{|c|}{ Whitehall II } & 42 \\
\hline 1 (least unemployment) & 1.00 & 1.00 & 1.00 & 1.00 \\
\hline 2 & $1.17(0.83$ to 1.65$)$ & $1.05(0.71$ to 1.56$)$ & $0.92(0.46$ to 1.86$)$ & $1.10(0.50$ to 2.43$)$ \\
\hline 3 & $1.40(1.00$ to 1.98$)$ & 1.21 (0.83 to 1.76 ) & $0.77(0.44$ to 1.50$)$ & $0.78(0.36$ to 1.66$)$ \\
\hline 4 (most unemployment) & $1.70(1.22$ to 2.36$)$ & 1.19 (0.79 to 1.78$)$ & $1.39(0.78$ to 2.46$)$ & 1.26 (0.64 to 2.46$)$ \\
\hline $\begin{array}{l}\text { Percentage reduction in hazard ratio } \\
\text { Helsinki }\end{array}$ & \multicolumn{3}{|c|}{ Helsinki } & 33 \\
\hline 1 (least unemployment) & 1.00 & 1.00 & & \\
\hline 2 & 1.21 (1.08 to 1.35$)$ & 1.14 (1.03 to 1.25$)$ & & \\
\hline 3 & $1.34(1.20$ to 1.50$)$ & 1.22 (1.11 to 1.34$)$ & & \\
\hline 4 (most unemployment) & $1.67(1.50$ to 1.86$)$ & 1.41 (1.28 to 1.55$)$ & & \\
\hline Percentage reduction in hazard ratio & & 39 & & \\
\hline \multicolumn{5}{|l|}{ Turin } \\
\hline 1 (least unemployment) & 1.00 & 1.00 & 1.00 & 1.00 \\
\hline 2 & 1.09 (1.03 to 1.16$)$ & 1.02 (0.96 to 1.09 ) & 1.06 (0.95 to 1.13$)$ & $1.04(0.97$ to 1.10$)$ \\
\hline 3 & $1.20(1.14$ to 1.27$)$ & 1.10 (1.02 to 1.18 ) & 1.14 (1.07 to 1.21 ) & 1.11 (1.04 to 1.18 ) \\
\hline 4 (most unemployment) & $1.28(1.23$ to 1.35$)$ & 1.14 (1.07 to 1.21 ) & 1.16 (1.09 to 1.24$)$ & $1.12(1.05$ to 1.20$)$ \\
\hline $\begin{array}{l}\text { Percentage reduction in hazard ratio } \\
\text { Madrid }\end{array}$ & & 50 & & 25 \\
\hline 1 Least unemployment & 1.00 & 1.00 & 1.00 & 1.00 \\
\hline 2 & 1.16 (1.00 to 1.32$)$ & $1.08(0.98$ to 1.19$)$ & $1.12(0.98$ to 1.26$)$ & $1.08(0.98$ to 1.18$)$ \\
\hline 3 & $1.25(1.07$ to 1.45$)$ & 1.10 (0.99 to 1.21 ) & $1.16(1.02$ to 1.30$)$ & $1.09(0.99$ to 1.20$)$ \\
\hline 4 Most unemployment & $1.52(1.30$ to 1.77$)$ & $1.28(1.16$ to 1.41$)$ & 1.35 (1.20 to 1.52$)$ & 1.24 (1.13 to 1.36$)$ \\
\hline Percentage reduction in hazard ratio & & 46 & & 31 \\
\hline
\end{tabular}

neighbourhood inequalities in mortality. It may explain to some extent that in women, significantly increased hazard ratios were found in Turin and Madrid only. Furthermore, using samples instead of whole populations increases the risk of selection bias if study participants are selected based on both neighbourhood characteristics and mortality risk. For example, a healthy worker effect in the occupation based cohort of Whitehall II may have contributed to some weaker evidence of an effect of neighbourhood unemployment on mortality in men, if Whitehall employees from high unemployment neighbourhoods differ systematically in mortality risk from other neighbourhood residents. Thirdly, the number of residents in the neighbourhoods varied from about 1000-2000 in the ARIC and GLOBE study to roughly 14000 residents in Helsinki. Theoretically, the larger the neighbourhood is, the greater the heterogeneity in terms of socioeconomic disadvantage. Reijneveld et al however, showed that odds ratios of a poor self rated health (and other self reported health outcomes) for living in the upper compared with the lowest tertiles of deprivation were similar for three areas differing in size (neighbourhoods, comparable to those in the GLOBE study, postcode sectors (for example, areas larger than neighbourhoods), and boroughs (in size more comparable to the areas used in Helsinki). ${ }^{17}$ We also found no substantial differences in associations of neighbourhood characteristics with mortality despite large differences in the definition of neighbourhoods across countries. Fourthly, differences in the classification of groups according to education and particularly occupation could not be avoided. This could have led to different degrees of adjustment for individual level socioeconomic indicators across studies. However, findings were comparatively similar across countries both before and after adjustment for individual level variables. With respect to this adjustment, it should also be mentioned that in some but not all studies data were available on individual level employment status. Additional adjustment for this employment status hardly changed the hazard ratios, and we therefore believe that we controlled sufficiently for socioeconomic factors at the individual level by including education and occupation.

\section{Key points}

- A pattern of increasing hazard ratios of mortality with increasing neighbourhood unemployment rates was found in samples in six countries.

- There was no evidence that the association between neighbourhood unemployment and mortality was substantially modified by country context among the six countries studied.

- Improving health of populations in general, and reducing socioeconomic inequalities in health, requires targeting on both people and places. 
Neighbourhood unemployment was used as an indicator of area deprivation in all studies. Although it was measured in essentially the same way in most countries the utility of unemployment as a marker of the area features directly relevant to health may differ between countries. We assessed the correlation coefficients between neighbourhood unemployment and other indicators of neighbourhood deprivation in all countries. Neighbourhood unemployment correlated inversely with neighbourhood income $(-0.51<r<-0.77$, $\mathrm{p}<0.01$ ) in all studies with available data (all but Whitehall II) and with the percentage owner occupied dwellings $(-0.43<r<-0.79, \mathrm{p}<0.01$ ) (available in all studies but Madrid), although the second association was not significant for Turin. Although these correlations suggest that unemployment is related to other measures of area deprivation in a similar direction in all countries, there may be differences in the country specific environmental correlates of area unemployment. Inclusion of other indicators of neighbourhood deprivation similarly defined across studies would have strengthened the analyses.

The ARIC study was the only study with a substantial number of participants from more than one race. To make all populations comparable, we restricted the analyses in the ARIC study to white people. Black people however, may reside more often in neighbourhoods with high unemployment rates, and premature mortality is higher in black people compared with white people. ${ }^{18}$ Thus, the results presented for the ARIC study may underestimate the overall association between area unemployment and mortality. Indeed, the analyses repeated with black and white subjects, showed higher hazard ratios. For example, the hazard ratio in the highest compared with the lowest quartile of neighbourhood unemployment was 1.59 (95\% CI 1.32 to 1.92 ) in men and 1.95 (95\% CI 1.49 to 2.56 ) in women, after adjustment for age, education, and occupation. After further adjustment for race the associations were similar to those observed in the other studies (the hazard ratio in the highest compared with the lowest quartile of neighbourhood unemployment was 1.30 (95\% CI 1.05 to 1.60 ) in men and 1.27 (95\% CI 0.94 to 1.71) in women).

Despite modest values and a less consistent pattern in women, our study showed increasing hazard ratios with increasing levels of neighbourhood unemployment in all studies after adjustment for age, education, and occupation. There are several reasons why differences in associations across countries might have been expected. Differences in the size of the associations could have occurred between countries because of differences in the absolute levels (and ranges in the levels) of deprivation. The large range in unemployment across studies did not permit the examination of categories with similar absolute cut offs so centile based categories specific to each study were used. This implies that the groups compared may differ by country. It is interesting to note the similarity in hazard ratios in Helsinki and Madrid despite the large differences in neighbourhood unemployment rates between these cities. This suggests that the way in which unemployment is distributed across cities influences the hazard of mortality, regardless of the absolute level of unemployment. Secondly, differences in the size of the associations could have been attributable to differences in

\section{Policy implications}

It is only after having obtained more insight in the mechanisms relating areas deprivation to mortality that policy recommendations can be formulated aimed at reducing the impact of the residential environment on health. degree of residential segregation by socioeconomic position, and differences between disadvantaged and advantaged neighbourhoods in terms of their physical and social environments between countries. However, adjustment for education and occupation did not result in substantial country differences in the associations. Thirdly, country level policies may contribute to increasing or attenuating neighbourhood effects on health. For example, the provision of welfare and public services may be of higher quality and more uniformly distributed in some countries, and may contribute to reducing the health impact of living in disadvantaged neighbourhoods. It has been argued, for example, that the stronger association between income inequality and mortality in the US compared with Canada may be explained by the universal availability of publicly funded services in Canada compared with the market led provision of services in the US. ${ }^{19}$ Our study, however, showed associations of similar sizes in the ARIC study and the studies in European samples despite differences in welfare and health policy.

The similarity in the (size of) associations in different countries makes it tempting to speculate about a general mechanism underlying the associations. For example, it is not unlikely that area deprivation is associated with similar processes involving health effects of the physical and social neighbourhood environment in all countries. Investigating selective migration processes, determined by either wealth or health across countries would also contribute to understanding the processes underlying the associations reported. It is also possible that the countries studied were not different enough in policies to permit detection of modification of area effects by country contexts. Examination in a broader range of countries may be necessary to detect if area differences are indeed modified by country level factors.

The general pattern found in this study adds to the growing recognition of a role of place for health. Improving health of populations in general, and reducing socioeconomic inequalities in health, requires targeting on both people and places, as soon as a sufficient understanding of the processes relating the neighbourhood socioeconomic environment to health is obtained. Although it needs to be recognised that contextual associations as investigated here will most probably always be to some extent dependent on the context in which they are investigated, our study provides a rationale for research on exploring general mechanisms for the association between area deprivation and mortality. It is only after having obtained more insight in the mechanisms relating areas deprivation to mortality that policy recommendations can be formulated aimed at reducing the impact of the residential environment on health. In conclusion, associations between neighbourhood unemployment (as a marker for area deprivation) and mortality were found in the US and five European countries, after adjustment for education and occupation at the individual level. There was no evidence that this association was modified by country context among the six countries studied.

\section{ACKNOWLEDGEMENTS}

The authors thank the staff and participants in all studies for their important contribution.

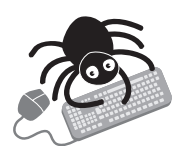

The appendix showing the classifications used for individual level education and occupation is available on line (http://www.jech.com/supplemental).
Authors' affiliations
F J van Lenthe, Department of Public Health, Erasmus Medical Centre Rotterdam, Rotterdam, Netherlands 
L N Borrell, Department of Epidemiology, Mailman School of Public Health, Columbia University, New York, USA

G Costa, Department of Public Health and Microbiology, Turin University, Turin, Italy

A V Diez Roux, Department of Epidemiology, University of Michigan, Ann Arbor, USA

T M Kauppinen, P Martikainen, T Valkonen, Department of Sociology, University of Helsinki, Finland

C Marinacci, Epidemiology Unit, Piedmont Region, Turin, Italy E Regidor, Department of Preventive Medicine and Public Health, Universidad Complutense de Madrid, Madrid, Spain

M Stafford, Department of Epidemiology and Public Health, University College London Medical School, London, UK

Funding: this study is the result of work carried out in Working group 3 ("Macrosocial determinants of morbidity and mortality: their contribution to the explanation of inequalities in health") of the Programme "Social Variations in Health Expectancy in Europe", funded by the European Science Foundation. FvL is supported by a grant from the Netherlands Organisation for Scientific Research (NWO grant number 904-66-\104). The GLOBE study is supported by grants of the Ministry of Public Health, Welfare and Sport and the Health Research and Development Council (ZonMw). ADR and LB were supported in part by RO1 HL64142 from the National Institutes of Health. The Whitehall II study has been funded by the MRC, BHF, and NIH. The Helsinki study was supported by the Academy of Finland (projects 51640, 70631, 48600). The study in Madrid was supported by a grant from the Fondo de Investigaciones Sanitarias (no 00/0514/1999).

Conflicts of interest: none declared.

\section{REFERENCES}

1 Pickett K, Pearl M. Multilevel analyses of neighbourhood socioeconomic context and health outcomes: a critical review. J Epidemiol Community Health 2001;55:111-22.

2 Bosma $\mathrm{H}$, Mheen $\mathrm{H}$ van de, Borsboom GJJM, et al. Neighborhood socioeconomic status and all-cause mortality. Am J Epidemiol $2001 ; 153: 363-71$.

3 Veugelers P, Yip AM, Kephart G. Proximate and contextual socioeconomic determinants of mortality: Multilevel approaches in a setting with universal health care coverage. Am J Epidemiol 2001;154:725-32.
4 Martikainen P, Kauppinen T, Valkonen T. Effects of the characteristics of neighbourhoods and the characteristics of people on cause specific mortality: a register based follow up study of 252000 men. J Epidemiol Community Health 2003;57:210-17.

5 Osler M, Prescott E. Educational level as a contextual and proximate determinant of all cause mortality in Danish adults. J Epidemiol Community Health 2003;57:266-9.

6 Borrell LN, Diez Roux AV, Rose K, et al. Neighbourhood characteristics and mortality in the atherosclerosis risk in communities study. Int J Epidemiol 2004;33:398-407.

7 Marinacci C, Spadea T, Biggeri A, et al. The role of individual and contextual socioeconomic circumstances on mortality: analysis of time variations in a city of north west Italy. J Epidemiol Community Health 2004;58:199-207.

8 The ARIC Investigators. The atherosclerosis risk in communities (ARIC) study: design and objectives. Am J Epidemiol 1989;129:687-702.

9 Mackenbach JP, Mheen $\mathrm{H}$ van de, Stronks K. A prospective cohort study investigating the explanation of socioeconomic inequalities in health in the Netherlands. Soc Sci Med 1994;38:299-308.

10 Marmot MG, Smith GD, Stansfeld S, et al. Health inequalities among British civil servants: the Whitehall II study. Lancet 1991;337:1387-93.

11 Cardano M, Costa G, Demaria M. Social mobility and health in the Turin longitudinal study. Soc Sci Med 2004;58:1563-74.

12 Regidor E, Gutierrez-Fisac JL, Calle ME, et al. Infant mortality at time of birth and cause-specific adult mortality among residents of the Region of Madrid born elsewhere in Spain. Int J Epidemiol 2002;31:368-74.

13 White AD, Folsom AR, Chambless LE, et al. Community surveillance of coronary heart disease in the atherosclerosis risk in communities (ARIC) study: methods and initial two years' experience. J Clin Epidemiol 1996;49:223-33.

14 Schrijivers CTM, Stronks K, Mheen $\mathrm{H}$ van de, et al. Explaining educational differences in mortality: the role of behavioral and material factors. Am J Public Health 1999;89:535-40.

15 OECD. International standard classification of education. Paris: OECD, 1997.

16 Reijneveld SA. Neighbourhood socioeconomic context and self reported health and smoking: a secondary analysis of data of seven cities. J Epidemiol Community Health 2002;56:935-42.

17 Reijneveld SA, Verheij RA, Bakker DH de. The impact of area deprivation on differences in health: does the choice of the geographical classification matter? J Epidemiol Community Health 2000;54:306-13.

18 Sorlie P, Rogot E, Anderson R, et al. Black-white mortality differences by family income. Lancet 1992;340:346-50.

19 Ross NA, Wolfson MC, Dunn JR, et al. Relation between income inequality and mortality in Canada and in the United States: cross sectional assessment using census data and vital statistics. BMJ 2000;320:898-902. 